\title{
HISTORICAL AND LOGICAL ANALYSIS OF APPROACHES TO THE PROBLEM OF INDIVIDUAL SUBJECTIVE POSITION FORMATION
}

(C) 2017

\author{
Garanina Reseda Muharramovna, candidate of pedagogical sciences, \\ senior lecturer of General, Bioinorganic and Bioorganic Chemistry Department \\ Samara State Medical University (Samara, Russian Federation)
}

\begin{abstract}
The following paper from the point of view of logical and historical approaches unity examines the objective conditionality of university students' subjective position formation and development process. From the logical point of view the author actualizes the idea of developing organization forms of teaching, educational, research and professional processes as a result of resolving contradictions in the design and construction of the educational process at the university. The process of a student's subject position formation appears to be in this case a necessary, adequate and effective tool for the removal of these contradictions. From the historical point of view the author deploys the idea of the retrospective analysis and synthesis of diverse points of view on the problem of student's subjective position formation and development. It provides access to the so-called integration of the theory of didactic encyclopedic knowledge, formalism and pragmatism, functional materialism, the theory of operational structuring, pedagogical theory of a holistic educational process, the theory of personality development, theories of selfdevelopment, copyrighted pedagogical systems of training and education. Logical approach realizes the idea of genesis of subjective position organizational forms and systems of formation as a kind of reaction to the contradictions that arise in the system of university educational space.

Keywords: historical and logical comprehension; competence approach; subject-role approach; integral characteristic; subject-subject interaction; subject activity; subject position of the student; self-determination; self-motivation; self-projecting; self-organization; self-development; self-management; self-realization; cognitive unit of human society.
\end{abstract}

УДК 378

\section{ИННОВАЦИОННАЯ ДЕЯТЕЛЬНОСТЬ ПЕДАГОГА В ПРОЦЕССЕ ЕГО ПРОФЕССИОНАЛЬНОГО СТАНОВЛЕНИЯ}

(C) 2017

\author{
Дири Марта Игоревна, аспирант кафедры психологии и педагогики \\ Самарский государственный технический университет (2. Самара, Российская Федераиия)
}

Аннотация. Рассматривается современное образование как основной фактор формирования нового качества экономики и общества, анализируются проблемы изменения содержания образования, актуализируются вопросы внедрения инновационных технологий в учебно-воспитательный процесс образовательных учреждений и изучение инновационной деятельности педагога как проявление его профессионального творчества. Отмечено, что профессиональное становление педагога является непрерывным процессом в течение всей жизни, который определяет возможность безграничного развития человека. Показано, что в зависимости от выбранного направления подготовки процесс профессионального становления имеет свои особенности, происходит в разнообразной совместной деятельности и общении субъектов образования. Проанализированы теоретические, экспериментальные и практически направленные исследования в области инновационной деятельности педагога, рассматривается инновационное развитие образовательного процесса. Подчеркивается, что профессиональная педагогическая общественность в большинстве своем сегодня состоит из педагогов, чье профессиональное становление началось в период индустриального развития общества, а также педагогов-стажеров, которые совсем недавно прошли стадию профессиональной подготовки. По этой причине возможности обеспечения готовности педагогических кадров к инновационной деятельности рассматриваются на различных этапах профессионального становления. Показывается, что понимание - осмысление - усвоение прежде всего теоретических знаний, а затем получение субъектом лично реализованного практического опыта позволяет развивать профессиональный и педагогический стиль мышления, обеспечивая инновационное обновление профессиональной деятельности педагога.

Ключевые слова: профессиональное становление; педагог; инновационная деятельность; инновационные технологии; творческий процесс; инновации; профессиональная деятельность; педагогическое становление; потенциал; профессиональные компетентности; профессионализм; профессиональное развитие; квалификации; личность.

В настоящее время такие исследователи, как В.А. Сластенин, Л.С. Подымова [1], К.Я. Вазина [2], Ю.Б. Дроботенко [3], М.В. Лагунова, Е.Э. Воропаева [4] и другие, отмечают, что проблема инновационной деятельности современного педагога становится все актуальнее. Радикальные социально-экономические изменения в стране повлекли за собой реформирование в системе образования государства и общества. Образование сегодня рассматривается как основной фактор в формировании нового качества экономики и общества, как существенное условие национальной безопасности, поддерживающее культурное пространство, благополучие и новый образ жизни. Следовательно, актуальными проблемами являются из- 
менения в контексте образования - введение инновационных технологий в учебных заведениях. Качество выбора решения для достижения стратегических и тактических целей в системе образования зависит в основном от профессиональной компетентности педагога. Педагоги обязаны создавать новый образ жизни: это означает быть основой культуры будущего, на которой будет основано образование современного поколения. Именно поэтому профессиональное становление педагога, его участие в процессе непрерывного самосовершенствования является важной проблемой на сегодняшний день. Процесс профессионального развития педагога может отвечать запросам развития современной системы образования только содержанием образования, формами и методами его организации, абсолютно новыми технологиями. Становление педагога включает в себя личностные и деловые качества, а также владение профессиональными компетенциями [5]. Кроме перечисленного, согласно В.Н. Аниськину и Е.Н. Рябиновой [6], в основу природосообразного образования личности должны быть положены базисные ценности - это, прежде всего, нравственность, следующая из природы самого человека.

Теоретические знания и их внедрение в практику позволяют развивать профессиональный и педагогический стиль мышления, обеспечивая инновационное обновление профессиональной деятельности. В связи с этим целью данного исследования становится изучение инновационной деятельности педагога как проявления его профессионального творчества. Для реализации поставленной цели необходимо определить сущность понятий «педагогическое становление» и «инновационная деятельность», проанализировать содержание и этапы инновационной деятельности педагога в сфере образования.

По словам Ю.В. Громыко, «инновация есть не что иное, как способ организации связей между принципиально новыми образами, культивируемыми и выращиваемыми на экспериментальной площадке, и огромным массивом традиционных практик. Инновации должны выполнить функцию обеспечения присвоения некоторого принципиально нового образца на достаточно больших и широких массивах практики с последующим его приживлением и сохранением». В этом определении автор не только обращает внимание на подлинную характеристику инновации (принципиально новое), но также ставит вопрос о репликации инновации в массовой практике, что является основанием для создания сети экспериментальных площадок [7, с. 545].

В.С. Лазарев и Б.П. Мартиросян под инновационной деятельностью понимают целенаправленное внедрение инноваций в систему образования в целях повышения качества образования. Субъектом инноваций ученые называют преподавательский состав или группу педагогов, участвующих в реализации этих инноваций. Содержание этой деятельности заключается в преобразовании школьной системы образования за счет этих нововведений. Их цель, по мнению В.С. Лазарева и Б.П. Мартиросяна, заключается в определении необходимости изменения си- стемы образования любого образовательного учреждения, поиск и эффективное использование существующего потенциала для реализации этих изменений [8, с. 17-25].

Ряд авторов, таких как В.В. Краевский [9], М.Н. Скаткин [10], Б.С. Гершунский [11], В.И. Журавлев [12], в своих работах рассматривают роль исследовательских компонентов инновационной деятельности педагога. Ученые считают, что для профессионального развития в области инновационных технологий педагог нуждается в научно-педагогической подготовке из-за отсутствия готового «сценария»; каждая ситуация уникальна, и педагог должен действовать независимо. Он должен быть исследователем. Особое место в исследованиях подготовки педагогических работников к инновационной деятельности упоминается в работах М.В. Кларина [13]. Ученый связывает профессиональное развитие педагогов с необходимостью непрерывного образования, организованного посредством разработки и реализации социальных и культурных проектов. Аксиология этого подхода заключается в ценностной ориентации личности на самоопределение, в котором образовательная деятельность занимает одно из ведущих мест и может быть основным ведущим средством личного развития. М.В. Кларин считает, что центральное место в профессиональном образовании и в подготовке педагога к инновационной деятельности занимает рефлексия. Автор раскрывает особенности творческого мышления и связывает его с рефлексией, что позволяет понять и обобщить опыт [14, с. 180]. Под рефлексией понимается (от лат. reflexio - обращение назад) способность человеческого мышления к критическому самоанализу. Различают несколько видов рефлексии. В частности, элементарная рефлексия заключается в рассмотрении и анализе индивидом собственных знаний и поступков. Такой вид рефлексии присущ почти каждому человеку: любой из нас хотя бы изредка задумывается над причинами собственных неудач и ошибок, с тем чтобы изменить свои представления о мире или об окружающих людях, исправить ошибки и постараться не допускать их в будущем. Рефлексия помогает нам учиться на своих ошибках. Научная рефлексия направлена на критическое исследование научного знания, методов и приемов получения научных результатов, на процедуры обоснования научных теорий и законов. Такая рефлексия находит выражение в специальных дисциплинах - логике, методологии научного познания, психологии научного творчества и т.п. [15, с. 165].

В своих исследованиях М.В. Каминская раскрывает психологическую сущность профессионального развития педагогов в процессе развития своей деятельности в области развивающего обучения. По её мнению, эта сущность лежит в «построении субъективности педагога, самоопределении его личности, способности к авторской интерпретации норм, ранее закрепленных в профессиональной культуре». Внутреннее психологическое условие профессионального развития педагога развивающего обучения «связано с развитием организации своего профессионального сознания от однопозиционного, внешнерефлексив- 
ного, к межпозиционному, диалогическому» [16, c. 34-43].

Представитель той же школы науки И.Д. Фрумин считает, что квалификационные характеристики педагогов системы развития обучения находятся во взаимосвязи с демократизацией образования. Автор утверждает, что образование является демократичным по своей натуре, так как образуется на общих интересах и включает в себя общение с другими личностями относительно решения проблем. Фактическим направлением в демократизации образования является поликультурность, что означает толерантность к другим культурам, то есть взаимодействие, взаимопонимание и взаимодополняемость. По мнению И.Д. Фрумина, педагог должен иметь следующие характеристики: выраженная гражданская позиция; ценностное самоопределение; демократический стиль своей работы, способность реагировать на запросы других; высокая коммуникативная культура при условии включения учащихся в планирование и регулирование образовательного процесса $[17$, с. 40 42]. В ходе анализа теоретических подходов к проблеме профессионального становления педагога, сосредоточенного на инновационной деятельности и практике инновационного образования, выяснилось, что В.А. Адольф и Н.Ф. Ильина выделили ряд условий, необходимых для успешной реализации этого процесса:

- повышение квалификации педагогов в области инноваций и поддержка должны быть основаны на компетентностном подходе;

- процесс профессионального становления педагога, занимающегося инновационной деятельностью, должен быть непрерывным, поскольку формирование инновационной практики постоянно изменяющийся процесс;

- профессиональное становление педагога, ориентированного на ведение инновационной деятельности, происходит за счет его участия в этой деятельности и специально организованных рефлексивно-аналитических, проектировочных, творческих и образовательных процессах;

- самообразование педагогического работника, который формирует свою деятельность на основе инноваций, должно быть организовано как непрерывный процесс достижения, в ходе которого идет решение поставленных задач и оформление новых;

- любая деятельность человека включает в себя решение задач, по этой причине целесообразно организовывать поддержку профессионального становления специалиста на основе решения им задач, присущих данному виду деятельности;

- для осуществления процесса профессионального развития каждому педагогу необходимо сформировать представление об инновационной деятельности в будущем, а также разработать совместную будущую деятельность и организовать освоение знаний, навыков, способов, необходимых ему для реализации этого процесса. Мероприятия по прогнозированию ближайших этапов инновационной деятельности, коллективная работа по предстоящей деятельности имеют образовательную значимость, по- скольку педагоги осваивают способы программирования и проектирования собственной деятельности, способы работы с представлениями других людей, совершенствуют коммуникативные умения и навыки, что является составной частью процесса профессионального становления педагога. Это служит основой инвариантной части индивидуальной образовательной программы педагога [18, с. 18-20].

Сущность процесса профессионального развития педагога состоит в пополнении индивидуальных образовательных дефицитов, возникающих в процессе его профессионального развития. Этот процесс включает в себя обогащение знаниями и навыками, формирование профессиональной компетентности, необходимой для успешной реализации инновационной деятельности путем подготовки и реализации индивидуальных образовательных программ. Анализ различных подходов к подготовке педагогов к инновационной деятельности в профессиональном развитии позволяет сделать следующие выводы:

- происходят изменения требований к педагогу: от профессионала, выполняющего сложные функции, от педагога-однопредметника к педагогуисследователю, поэтому необходимо обеспечить объективные и субъективные условия для актуализации индивидуального потенциала профессионального развития, в которых педагог осознает себя субъектом собственного личностно-профессионального развития и проявляет профессиональную инициативу, выступающую показателем и способом личностнопрофессионального развития;

- ранее частные знания педагогов в области преподавания своего предмета, в области педагогики и психологии, а также профессиональное мастерство являлись значимыми характеристиками педагога. Но на сегодняшний день актуальными являются системное мировоззрение, инновационное мышление и профессиональная творческая работа;

- для готовности к инновационной деятельности в процессе профессионального развития неотъемлемо создание условий для формирования научноисследовательских и коммуникативных компетенций, рефлексивных навыков, мотивации педагога для ведения инновационной деятельности;

- сегодня требует пересмотра стратегия подготовки педагога к инновационной деятельности, предусмотренной действующим социальным положением, практикой современного образования, изменением ценностей в обществе в целом.

Для обеспечения качества профессионального педагогического обучения возникает потребность создания информационной образовательной среды, направленной на моделирование профессиональной деятельности будущего педагога. Можно выделить следующие цели функционирования такой среды:

- формирование и развитие познавательной деятельности образовательного процесса;

- формирование профессионального и педагогического стиля будущего педагога в контексте профессиональной компетентности;

- формирование готовности к самообразованию будущих педагогов; 
- формирование готовности будущих педагогов к использованию информационно-коммуникационных технологий (ИКТ) в своей профессиональной деятельности.

Педагогическая деятельность относится к группе профессий «человек-человек», которая требует владения следующими качествами: желание общаться; умение легко вступать в контакт; сдержанность при работе с людьми; доброта; отзывчивость; выдержка; умение контролировать свои эмоции; способность анализировать свое поведение и поведение других людей, чтобы понимать их намерения и настроение; способность понимать взаимодействие людей, чтобы регулировать разногласия между ними, организовывать их взаимодействие; способность мысленно поставить себя на место другого человека; умение слушать и учитывать мнения других; умение правильно использовать свою речь, выражения лица, жесты; способность находить общий язык с разными людьми, убеждать людей; аккуратность; пунктуальность; самодисциплина; знание человеческой психологии. Многие высокие должности требуют большинство вышеупомянутых способностей, так что они могут быть отнесены не только к личным, но и к управленческим качествам человека.

На современном этапе модернизации образования в нашей стране основные направления государственной политики направлены на цели повышения качества образования как основы жизни человека и общества в целом. Страна движется к постиндустриальному миру, в котором правит триада образование-наука-инновации. Наши знания - это результат нашей работы, чем больше педагоги работают и стремятся к самообразованию, тем лучше для них, тем больше они будут знать. Знание рассматривается как экономический ресурс государства, фактор производства. Модернизация национальной системы образования происходит постоянно, в результате чего она приближается к международным стандартам. Теперь можно установить подходы к противоречивой природе терминов «качество образования» и «результаты образовательного процесса». Современные исследования качества образования следующие:

- социальная категория, которая определяет статус и эффективность процесса образования в обществе, отвечает потребностям и ожиданиям общества в развитии и формировании гражданского потребителя и профессиональной компетентности личности;

- удовлетворение ожиданий различных участников образовательного процесса в учреждениях, оказывающих образовательные услуги;

- степень достижения поставленных целей и задач образования;

- соответствие результатов, принятых доктриной образования, социальными нормами и требованиями государства и личности;

- набор существенных признаков и характеристик результатов обучения, которые могут удовлетворить потребности обучающихся, общества и других потребителей образовательных услуг.

Качество высшего образования определяется соответствием целей высшего образования, требовани- ями социально-экономического развития страны, улучшением качества интеллектуальных и в целом человеческих ресурсов, приоритетами технического развития и в общем экономикой знания, необходимостью развития личности и требованиями обеспечения конкурентоспособности специалистов на рынке труда и общей конкурентоспособности страны [19].

Разработка показателей профессионального развития будущих педагогов позволила ученым В.А. Адольфу и Н.Ф. Ильиной выделить ряд основных принципов, а именно: «уровень подготовленности специалистов в области образования целесообразно определить на основе решения специально разработанных профессиональных задач», «показатели готовности должны оценивать не только результат профподготовки, но и весь процесс становления специалиста на различных этапах и уровнях непрерывного образования». Оценка уровня профессионального становления специалиста должна осуществляться в соответствии с основными функциями, характерными для профессиональной педагогической деятельности. [20, с. 310]. Выделяют следующие характерные функции педагогической деятельности: диагностическая, информационная, конструктивно-проектировочная, организационно-коммуникативная, прогностическая, а также исследовательская и оценочная. Чтобы проверить уровень мастерства, необходимо представить каждую из этих функций в виде операционных компонентов [21, c. 190].

В результате проделанного анализа научных работ, касающихся особенностей инновационной деятельности, можно выделить ряд критериев для профессионального развития педагога в процессе инновационной деятельности:

- формирование профессиональной компетентности, представленной следующими компонентами: мотивационный и ценностный, коммуникативный, организационный, управленческий, методический, научно-исследовательский и рефлексивный;

- овладение компонентами общего образования, основами теории и практики инновационной технологии, с которой необходимо работать;

- способность к инновационному обучению [22; 23].

Требования к современному педагогу, к его способности быстро и относительно безболезненно приспособиться к постоянному ускорению развития общества усиливает ценность его готовности к работе с инновациями. В постиндустриальном обществе с его новыми образовательными моделями педагогу важно быть инновационным, принимая происходящие изменения и развитие образовательной среды.

Главная цель инновационной деятельности - развитие педагога как творческой личности, переключение его с репродуктивного типа деятельности на самостоятельный поиск методических решений, превращение педагога в разработчика и автора инновационных методик и реализующих их средств обучения, развития и воспитания. 
Руководство инновационной деятельностью осуществляется в различных формах: главным принципом руководства является поддержка педагога различными средствами, как образовательными (педагогическая учеба, консультации, семинары и т.д.), так и материальными (различные формы доплат, премий и т.д.) Одним из наиболее важных моментов является разворачивание среди педагогов процесса рефлексии и понимания относительно собственной педагогической деятельности.

За любым новшеством предполагается наличие инновационно-педагогической деятельности конкретного педагога. Следовательно, необходимо создание условий для педагогического творчества, совершенствования форм и методов обучения и воспитания, необходимо обеспечение вариативности в отборе содержания.

Участие педагога в инновационной деятельности противоречиво. С одной стороны, это должно быть полезно для его профессионального развития, так как позволяет освоить новые педагогические технологии, приобрести новый педагогический опыт, а с другой стороны - инновационная деятельность связана с преодолением трудностей различного типа, в том числе и способных привести педагога к кризису профессионального развития.

Наблюдения показывают, что для эффективного обеспечения процесса непрерывного профессионального развития педагога - как преподавателяспециалиста в предметной области, как педагогавоспитателя, как педагога-исследователя, наконец, как педагога-новатора - необходимы по крайней мере следующие два основных фактора:

1) психологическая готовность педагога к инновационной деятельности и, как показывают наши исследования, особая группа навыков и умений рефлексивно-аналитического и деятельностно-практического порядка;

2) переориентация всех институционализированных форм профессионального образования, повышения квалификации педагога на задачи поддержки его как педагога-профессионала в стремлении к непрерывному профессиональному росту.

Высокие достижения педагога в профессиональной деятельности существенно развивают его личность. Занимаясь инновационной деятельностью, развивая инновационную активность, создавая чтото значительное, новое, достойное внимания, педагог и сам растет, поскольку «в творческих, доблестных делах человека - важнейший источник его роста». С другой стороны, чем проще, однороднее деятельность, выполняемая преподавателем, чем меньше поле проявления его активности, тем в меньшей степени оказывается развитой его личность. Ведь человек, выполняющий всю жизнь простые операции, не требующие напряжения умственных способностей, в конце концов собственноручно деформирует свою личность. Успех в инновационной деятельности педагога зависит от многих факторов: направленности или характера мотивации его педагогической деятельности, креативности педагога, уровня развития его личных и профессиональных качеств, от наличия или отсутствия определенных барьеров на пути у педагога и от психологического климата в педагогическом коллективе.

Все факторы, рассмотренные выше, должны быть учтены педагогами и его научными руководителями при планировании и осуществлении его инновационно-педагогической деятельности, так как в совокупности они составляют общую систему требований к становлению педагога и его новаторства. Выстраивается новая логика профессионального становления педагога, обеспечивающая его целостность с позиций профессиональной компетентности и направленная на постоянное обновление культурной среды образовательного учреждения, оказывая влияние на повышение инвестиционной привлекательности образования.

\section{СПИСОК ЛИТЕРАТУРЫ:}

1. Сластенин В.А., Подымова Л.С. Педагогика: инновационная деятельность. М.: Изд-во «Магистр», 1997. C. 220-224.

2. Вазина К.Я. Модель непрерывного саморазвития человека // Авторские программы обучения педагогов нового типа. Оренбург: Изд-во ОГУ, 2012. $23 \mathrm{c}$.

3. Дроботенко Ю.Б., Дука Н.А., Дука Т.О., Чекалева Н.В. Инновационные процессы: учеб. пособие для студ. магистратуры. Омск: ФГБОУ ВПО ОмГПУ, 2013. $131 \mathrm{c}$.

4. Лагунова М.В., Воропаева Е.Э. Готовность педагога к инновационной деятельности // Материалы I междунар. науч.-практ. конф. М.: НИЦ «Апробация», 2013. С. 161-167.

5. Дири М.И. Анализ изучения эффективности инновационной деятельности педагогов как средства повышения качества образовательного процесса // Актуальные проблемы психологии и педагогики: XI междунар. науч.-практ. конф. «Актуальные проблемы гуманитарных и социально-экономических наук». Ч. 7. Вольск: Изд-во «Перо», 2017. С. 149-152.

6. Аниськин В.Н., Рябинова Е.Н. Решение учебновоспитательных проблем при изучении математики в вузе // Самарский научный вестник. 2016. № 3 (16). C. 141-147.

7. Громыко Ю.В. Проектирование и программирование развития образования. М., 1996. $545 \mathrm{c}$.

8. Лазарев В.С., Мартиросян Б.П. Нормативный подход к оценке инновационной деятельности школы // Педагогика. 2003. № 3. С. 17-25.

9. Краевский В.В. Соотношение педагогической науки и педагогической практики. М.: Знание, 1977. $64 \mathrm{c}$.

10. Скаткин М.Н. Совершенствование процесса обучения. М.: Педагогика, 1971. 200 с.

11. Гершунский Б.С. Философия образования XXI века (в поисках практико-ориентированных образовательных концепций). М.: Совершенство, 1998. $608 \mathrm{c}$.

12. Журавлев В.И. Взаимосвязь педагогической науки и практики. М.: Педагогика, 1984. 176 с.

13. Кларин М.В. Педагогические технологии и инновационные тенденции в современном образова- 
нии // Инновационное движение в российском школьном образовании. М.: Изд-во «Парсифаль», 1997. С. 336-353.

14. Кларин М.В. Педагогическая технология в учебном процессе. Анализ зарубежного опыта. М.: Знание, 1989. 180 с.

15. Философия: Энциклопедический словарь / под ред. А.А. Ивина. М.: Гардарики, 2004. 1072 с.

16. Каминская М.В., Эльконина Д.Б., Давыдова В.В. Концепция профессионального развития учителя в системе развивающего образования // Психологическая наука и образование. 2004. № 3. С. 34-43.

17. Фрумин И.Д. Введение в теорию и практику демократического образования. Красноярск: Знание, 1998. С. $40-42$.

18. Адольф В.А., Ильина Н.Ф. Подготовка педагога к инновационной деятельности в процессе профессионального становления. М.: Альма-Матер, 2006. № 10. C. 18-20.

19. Дири М.И. Значимость инновационных преобразований при подготовке современных специалистов // Современные технологии подготовки кадров и повышения квалификации специалистов нефтегазового производства: тез. IV научно-практической конференции с междунар. участием. Самара, 2017. C. 23.

20. Адольф В.А. Профессиональная компетентность современного учителя: монография. Красноярск, 1998. 310 с.

21. Адольф В.А., Ильина Н.Ф. Инновационная деятельность педагога в процессе его профессионального становления. Красноярск: Поликом, 2007. $190 \mathrm{c}$.

22. Рябинова Е.Н., Марченкова Л.А. К вопросу об актуальности формирования вербальных компетенций студентов технических вузов // Вестник Самарского государственного технического университета. Серия «Психолого-педагогические науки». 2015. № 2 (26). С. 163-170.

23. Рябинова Е.Н., Марченкова Л.А. Формирование вербальных компетенций в процессе профессиональной подготовки будущих инженеров // Вектор науки ТГУ. Серия: педагогика, психология. 2015. № 4(23). С. 158-163.

\section{EDUCATOR'S INNOVATIVE ACTIVITY IN THE COURSE OF PROFESSIONAL TRAINING}

(C) 2017

Diri Marta Igorevna, postgraduate student of Psychology and Pedagogy Department Samara State Technical University (Samara, Russian Federation)

Abstract. The paper deals with modern education as a major factor of new quality formation of economy and society. The author analyses problems of education content change, problems of innovative technologies introduction in teaching and educational process. A teacher's innovative activity as manifestation of his/her professional creativity is also studied. It is noted that professional training of a teacher is a continuous life-long process which defines a possibility of a person's boundless development. It is shown that the process of professional training has some features, occurs in joint activity and communication. Theoretical and experimental researches in the field of a teacher's innovative activity are analyzed, innovative development of the educational process is considered. The author emphasizes that today the majority of professional pedagogical public consists of teachers whose professional training began during industrial development of society, as well as teachers-trainees who quite recently passed a stage of vocational training. For this reason, possibilities of ensuring readiness of pedagogical personnel for innovative activity are considered at different stages of professional training. The author shows that understanding of theoretical knowledge and then obtaining practical experience allows to develop professional and pedagogical style of thinking, provide innovative updating of a teacher's professional activity.

Keywords: professional training; educator; innovative activity; innovative technologies; creative process; innovations; professional activity; pedagogical formation; potential; professional competences; professionalism; professional development; qualifications; personality.

УДК 378.09

\section{ФОРМИРОВАНИЕ ОРГАНИЗАТОРСКИХ СПОСОБНОСТЕЙ В СФЕРЕ ПРЕДПРИНИМАТЕЛЬСКОЙ ДЕЯТЕЛЬНОСТИ У БУДУЩИХ СОТРУДНИКОВ ПЕНИТЕНЦИАРНОЙ СИСТЕМЫ}

(C) 2017

Ежова Олеся Николаевна, кандидат психологических наук, профессор кафедры управления и информационно-технического обеспечения деятельности УИС

Улендеева Наталия Ивановна, кандидат педагогических наук, доцент кафедры управления и информационно-технического обеспечения деятельности УИС Самарский юридический институт ФСИН России (2. Самара, Российская Федеращия)

Аннотациия. В статье анализируются условия и требования, предъявляемые к организации производственной деятельности в учреждениях пенитенциарной системы на современном этапе развития социальноэкономических отношений, предполагающие необходимость формирования у сотрудников организаторских способностей в предпринимательской деятельности. Рассмотрены подходы к определению организаторских 